\title{
The Future Scenario of Creating a Digital SME Community in the Irish Construction Industry
}

\author{
Alan V. Hore \\ Technological University Dublin, alan.hore@tudublin.ie \\ Roger West \\ Trinity College, rwest@tcd.ie \\ Alan Redmond \\ Technological University of Dublin, d99101075@mydit.ie
}

Follow this and additional works at: https://arrow.tudublin.ie/beschreccon

Part of the Construction Engineering and Management Commons

\section{Recommended Citation \\ Hore, A.V., West, R.P. and Redmond, A., (2009), The Future Scenario of Creating a Digital SME Community in the Irish Construction Industry, 26th CIBW78 Conference, Managing IT in Construction, Istanbul, Turkey, 30th September - 3rd October 2009, Edited by Dikbas A., Ergen E. And Giritli, H., CRC Press, pp.121-130. doi:10.21427/v41q-na96}

This Conference Paper is brought to you for free and open access by the School of Surveying and Construction Management at ARROW@TU Dublin. It has been accepted for inclusion in Conference papers by an authorized administrator of ARROW@TU Dublin. For more information, please contact arrow.admin@tudublin.ie, aisling.coyne@tudublin.ie,gerard.connolly@tudublin.ie.

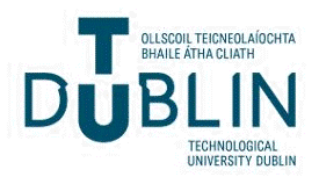




\title{
The Future Scenario of Creating a Digital SME Community in the Irish Construction Industry
}

\author{
A.V. Hore \\ Dublin Institute of Technology, Dublin, Ireland \\ R.P. West \\ Trinity College, Dublin, Ireland \\ A. Redmond \\ Dublin Institute of Technology, Dublin, Ireland
}

\begin{abstract}
The problems associated with the Construction Industry not being able to manage and communicate electronically product and project data between collaborating firms and within individual companies is compounded by the large number of small companies that have not adopted advanced Information Communication Technology (ICT). The typical nature of the service provided in construction, being an on-site and often highly customised service are generally identified as the reason for the low ICT uptake. The majority of Irish companies in the construction sector are Small to Medium sized Enterprises (SMEs). As eBusiness opens up the Irish economy to international competition Irish SMEs should use ICT as a generator of competitive advantage to become more effective and efficient with eBusiness technologies. The Construction IT Alliance in Ireland has identified a programme that can create a digital SME community that will promote ICT services in the Irish Construction Industry in order to compete in the global economy.
\end{abstract}

\section{INTRODUCTION}

The National Economic Social Council (2004) reported that additional housing output had been predicted for the next decade with the balance between supply and demand being achieved in the coming years but it was not clear when the annual housing market output would begin to decline (NESC, 2004). Forward to 2009 and this decline is clearly evident as a sharp downward adjustment has been recorded since the height of the Irish construction industry boom in 2006. According to the Irish government (NSRF, 2007) a part of the National Strategic Reference Framework is the Commission drafted Community Strategy Guidelines (CSG) which purpose is to define key priorities for EU Regional Policy over the period 2007-2013. Such priorities are to promote and encourage innovation, the knowledge economy, research and ICT (NSRF, 2007). The significance of these priorities is now substantial with the highest unemployment figures now reported in 11 years. This downward adjustment has made traditional Irish based companies move to selling products and services internationally. The need for Irish companies to be more effective and efficient with eBusiness technologies to compete with their competitors was the main incentive for this project.

The authors will present the results of a recently completed research project, the Construction IT Alliance eXchange (CITAX) project. In 2006 CITA set about to identify the potential for efficiencies that would lead to savings and faster delivery through the implementation of eBusiness in the construction industry. Gatautis and Vitauskaitè (2008) posited that the use of e-Business in the construction sector is very limited and the potential of e-Business to increase productivity and efficiency is not exploited.

Software is very widely used today, yet its instrumental role in the modern digital economy is often overlooked. With market revenues of over $€ 200$ billion in Europe and growth rates of between 6 and $8 \%$, software is the largest and the fastest growing segment of the ICT market. However, European companies rarely become global leaders, as it is difficult to grow fast enough in an increasingly globalised market (European Commission, 2009).

An essential aspect of this paper will analyse various vendors currently available in the eBusiness and eTendering market and identify related international research before addressing ICT need analysis. In conclusion this paper sets out a strategy for the newly funded Enterprise Innovation Network (EIN) research project secured by CITA which focuses on the ICT needs of SMEs in the Irish construction industry. The radical concept of a virtual market for SMEs in the construction industry through the implementation of Software as a Service (SaaS) will be presented as a future scenario solution. This solution will assist the increasing practice of ICT by SMEs to compete on the global stage with equal ability as the large enterprises. CITA research in identifying and analysing this innovative concept will enable SMEs with greater efficiency in exporting their services and products. 


\section{ICT UP-TAKE BY SMES IN THE CONSTRUCTION INDUSTRY}

According to Gallaher et al (2004), the paper system is still the most common medium for storing and transferring information. The introduction of computer use has done little to create the "paperless office." The fact remains that many of the key decisions makers in organisations do not fully appreciate the interrelated nature of the business processes that support the facility life cycle. The report identifies that interoperability issues occur creating a fragmented business process and organisational structure. It is estimated that the cost of inadequate interoperability in the U.S capital facilities industry is $\$ 15.8$ billion per year. In 2002, the value of capital facilities set in place in the U.S was $\$ 374$ billion. The significant magnitude of this figure presents the ideology that even small improvements in efficiency potentially represent significant economic benefits. In recognising that ICT has the potential to revolutionize the industry and streamline historically fragmented operations the report states that tools such as computer-aided drafting technologies, 3-D modelling technologies, and a host of Internet and standards based design and project collaboration technologies can reduce the fragmented nature of the industry. However, the problems associated with not being able to manage and communicate electronic product and project data between collaborating firms and within individual companies is compounded by the large number of small companies that have not adopted advanced ICT (Gallaher et al, 2004).

In Becerik (2004), the internet connectivity and the general use of email and the World Wide Web are viewed as being substantially high in the construction industry. However, Becerik accepts that many other studies demonstrate that new technologies are adopted slowly and ineffectively in the Architect, Engineering and Construction (AEC) industry. For example 2D Computer-Aided-Design (CAD) was in the market for almost four decades before it became pervasive. 3D is a well-established technology that is only now beginning to enter the main stream. 4D CAD, an incorporation of 3D CAD and time, has started to be used by the innovators of the industry. It appears that larger manufacturing firms are more innovative towards the adoption of new technology than AEC firms, possibly by 3 to 5 years. Becerik acknowledges that there may be many reasons why this is the case. The need for a rapid shift in terms of new technology adoption in AEC industry would certainly be a positive contributor to this adoption process (Becerik, 2004).

According to an Irish government (DETE, 2004) report Ireland was identified as one of the first countries to recognise the potential and challenges of the Internet, with the establishment of an Information Society Commission in 1998, and publication of the
Government's first Action Plan for the Information Society. This plan focused on the development of the telecommunications infrastructure and regulatory environment, developing eBusiness opportunities, delivering public services electronically and generally stimulating widespread society engagement with the Internet. The report acknowledged that Ireland has a very strong ICT producing sector and has the potential and opportunity to become a world leader in the emerging digital sectors. However, the performance is less than impressive when it comes to the adoption of ICTs by existing enterprises in the non ICT related sectors of the economy. The report suggests that as eBusiness opens up the Irish economy to international competition Irish enterprises should use ICT as a generator of competitive advantage in the context of the environment they operate in and companies should have ICT systems that are robust and secure in order to obtain maximum benefit.

It was reported in an e-Business W@tch (2006) report that the construction industry is a sector where ICT and e-business are used to a lesser extent than in most other sectors. The two reasons identified for low ICT uptake are:

\section{The high concentration of SMEs in the construc- tion industry and \\ - The typical nature of the service provided in con- struction, being an on-site and often highly cus- tomised service.}

The eBusiness W@tch 2006 survey data suggested that large construction enterprises are increasing their focus on ICT issues, such as e-procurement systems, collaborative design systems and collaborative document sharing. However, it also stated that there was a low percentage of firms employing ICT as well as a low adoption of Enterprise Resource Planning (ERP) software and advanced eprocurement solutions. The survey also mentioned that construction industry enterprises have little focus on hiring ICT practitioners and ICT training and that the use of eStandards are limited in the construction industry but about in line with the weighted all-sectors average (eBusiness W@tch, 2006).

Hore and West (2005) reported that building materials account for up to $50 \%$ of all construction costs and in the field of business to business (B2B) interactions there is a huge untapped potential for productivity gains. Technologies such as Automatic Identification (Auto-I) and bar coding have become widespread within manufacturing, medicine and retail industries but in comparison with the construction industry adoption worldwide it is very piecemeal. Hore and West carried out a survey of over 100 Irish construction companies. The survey analysed the current level of technology uptake in B2B purchasing transactions between building contrac- 
tors and material suppliers; the driving forces which attract firms to adopt electronic purchasing; the barriers of such adoption and the future development in adopting technology within the Irish supply chain. The key results illustrated a low level of awareness of appropriate technologies and the absence of appropriate industry standards. The need for an increase in the ICT literacy skills of purchasing staff and familiarity with electronic purchasing was also recommended (Hore and West, 2005).

The problems associated with fragmentation of the construction process and the adoption of Construction Collaboration Technologies (CCT) was identified by Duffy et al (2007). Analysing from an Irish context, the potential benefits of what CCT had to offer the construction industry were beginning to be realised. Duffy et al claimed that the construction industry was actively involved in the work of CITA in order to seek and improve the use of ICT, including CCT. However, the paper also states that the problems of fragmentation and resulting levels of poor communication and information exchange are not limited to the larger organisations. The lack of distinct research into the possibilities for the adoption of CCT within the SMEs involved in project management roles in Ireland was the main focus of the paper. From this platform an outline of future research would be proposed taking into consideration the potential barriers to adopting CCT within the SMEs project management roles. The expected outcome of the research was a proposed framework for the implementation of CCT in SMEs engaged in construction project management (Duffy et el, 2007).

\section{CONSTRUCTION IT ALLIANCE EXCHANGE PROJECT}

\subsection{Background to CITAX}

CITA was established as a research project in Dublin Institute of Technology (DIT) in association with the Waterford Institute of Technology (WIT) in May 2001 , with the vision of harnessing the potential of ICT in the Irish Construction Industry. CITA was formally incorporated into a company limited by guarantee with no share capital in November 2005. Membership of CITA is open to all stakeholders in the Irish construction industry who all share the CITA vision and want to participate in fulfilling CITA's objectives.

CITA has identified its objectives as:

- To inform the Irish construction sector of ICT developments.

- To establish and disseminate good practice in the use of ICT in the Irish Construction Industry.
- To encourage ICT related research collaboration between Irish academia and Irish construction practitioners.

- To establish and maintain links with relevant national and international organizations.

- To encourage the strategic use of IT by all firms in the Irish Construction Industry.

\subsection{Research work completed to date}

In July 2006 CITA initiated the CITAX project as an industry-led networking pilot project. The CITAX project involved a collaboration of 25 industry partners and a government body. The project aimed to demonstrate that significant measurable economic improvements could be achieved by using readily available ICT tools to radically improve business processes in the Irish Construction Industry. The project was supported by Enterprise Ireland (50\%) and CITA membership (50\%) and was completed in June 2008. The project consisted of five separate but collaborative modules, namely:-

\section{Module 1 - Design \\ Module 2 - Trading \\ Module 3 - Electronic Tendering \\ Module 4 - Project Collaboration \\ Module 5 - Computer Aided Measurement (CAM)}

Each of the modules had clear objectives and by demonstrating these objectives their achievements set out steps for future goals. The general conclusion was that clear economic benefits could be achieved through the pilot projects associated with the modules.

\subsection{Research Findings}

The aim of the CITAX project was to prove that the benefits of widespread ICT deployment within the construction sector would benefit all companies participating in electronic exchange and cooperation. The strength of the project involved both ICT providers and companies from both sides of the construction sector. (Hore and West, 2008).

CITAX Module 1 (Design) team set out to demonstrate that there were clear economic benefits to be achieved by organisations that exchanged drawings electronically using an agreed layering convention. The team was successful in achieving this and significant savings were identified and verified by the team through a pilot that the team undertook on a commercial project. The results indicated typical savings in time between $44 \%$ and $51 \%$ to clean up drawings and cost savings of $76 \%$ for high estimate - complex drawings equating to $€ 156,000$ typical annual cost and $68 \%$ for low estimate - simple drawings equating to $€ 47,833$ typical annual cost. These costs are based on 100 jobs, which have 
50 drawings that did not confirm to an agreed layering convention. Table 1 below illustrates the High and Low Estimated Costs associated with CITAX Module 1:

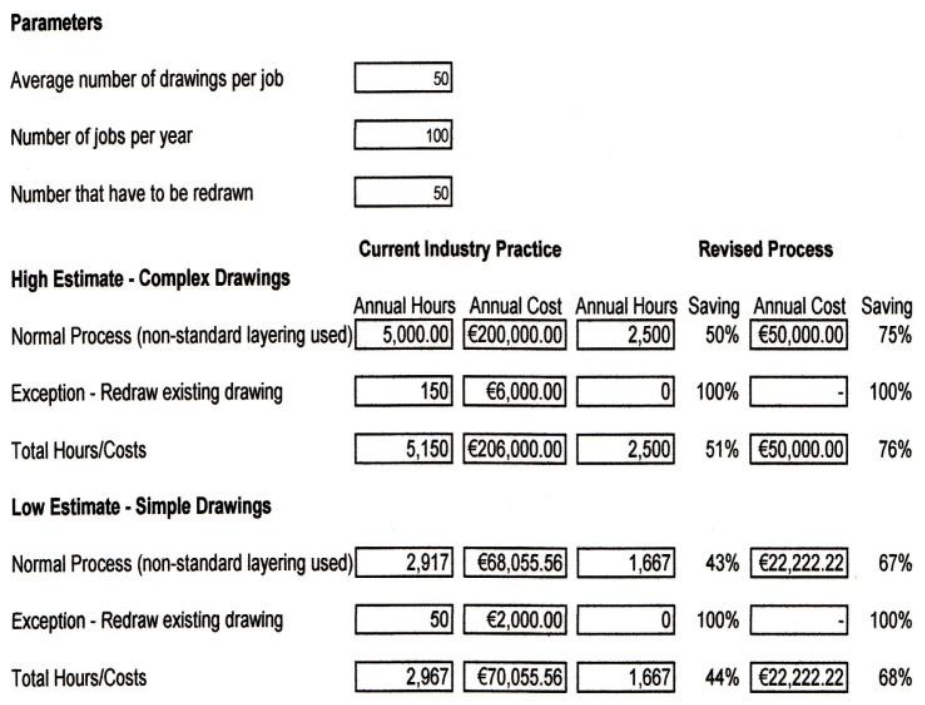

Table 1. High and Low Estimate Costs

CITAX Module 2 (Electronic Trading) was established to verify that significant measurable economic benefits could be achieved by collaborating trading networks members on a live project by the adoption of an XML standard. Having validated the process flows, time impact, and costs of the existing process the team devised a revised process undertaking a costing exercise to estimate the cost of the revised process, which would be compared to the estimate of the current process. The team examined technologies such as EDI (Electronic Data Interchange) before deciding that eBuild XML (eXtensible Markup Language) BASDA was the most appropriate one for the needs of the Irish construction industry. The cost savings identified were very significant for both contractor and suppliers with administration savings of $80 \%$ in both cases. An example saving of $€ 280,139$ on the estimated revised cost for the contractor compared to its current cost of $€ 346,552$ and a saving of $€ 90,254$ on the estimated revised cost for the supplier compared to its current cost of $€ 111,030$.

CITAX Module 3 (Electronic Tendering) team aimed to demonstrate that there were clear economic benefits to be achieved by organisations that replaced the traditional paper-based system with an electronic tendering process. A pilot scheme was undertaken using FTP (File Transfer Protocol) technology and the results showed typical savings of $11 \%$ for Professional Quantity Surveying firms, which equates to a saving across the industry of $€ 0.74 \mathrm{~m}$ per annum; $10 \%$ for contractors on their tender costs, which equates to an industry saving of $€ 4.8 \mathrm{~m}$ per annum and $11 \%$ for sub-contractors, which equates to an industry saving of $€ 3.75 \mathrm{~m}$ per annum. Table 2 indicates the savings accumulated from using eTendering:

\begin{tabular}{|c|c|c|c|c|c|c|}
\hline \multirow{2}{*}{$\begin{array}{l}\text { Cost Comparison } \\
\text { Current Company Cost per Tender }\end{array}$} & \multicolumn{2}{|r|}{$P Q S$} & \multicolumn{2}{|c|}{ Main Contractor } & \multicolumn{2}{|c|}{ Sub-Contractor } \\
\hline & $€$ & $6,732.50$ & $€$ & $9,575.00$ & $€$ & 225.00 \\
\hline Estimate of Revised Costs per Tender & $€$ & $5,995.50$ & $€$ & $8,612.50$ & $€$ & 200.00 \\
\hline Cost Saving per Tender & $€$ & 737.00 & $€$ & 962.50 & $€$ & 25.00 \\
\hline Precentage Saving & & $11 \%$ & & $10 \%$ & & $11 \%$ \\
\hline Current Industry Cost & & $, 732,500.00$ & $€ 47$ & $875,000.00$ & & $50,000.00$ \\
\hline Revised Industry Cost & & $995,500.00$ & $€ 4^{3}$ & $062,500.00$ & & $000,000.00$ \\
\hline Industry Saving per Year & $€$ & $37,000.00$ & $€$ & $2,500.00$ & & 00.00 \\
\hline
\end{tabular}

Table 2. Estimated Cost Savings

CITAX Module 4 (Project Collaboration) aimed to verify that significant measurable economic benefits can be achieved by collaboration between members of a project team, by adopting an online collaboration tool on construction projects. The findings of the research indicated that main contractors normally drive the use of project collaboration software and that the main implementations of the software are limited to individual projects depending on size and project duration. The overall cost to the project is reduced due to the fact that information is only printed as it is required, eliminating the production of unnecessary copies. The use of project collaboration software can reduce the length of time to address queries by 50-60\% over traditional paper processes; it was difficult to accurately quantify the cost savings to the project.

CITAX Module 5 (Computer Aided Measurement) team set out to verify that significant measurable economic benefits can be achieved by Quantity Surveying network members by the use of computer aided measurement in the production of a Bill of Quantities on a live project. Due to commercial sensitivities of establishing a definitive cost associated with the production of typical bills of quantities the team took the decision not to include actual costs within the report. The pilot participants measured commercial projects both manually and electronically. In general the outcome of the pilot confirmed that time savings of between $57 \%$ and $70 \%$ are possible.

The European Commission report Sectoral eBusiness Policies in Support of SMEs (2007) commended the fact that CITAX used live pilot projects to show real benefits of eBusiness for the industry (European Commission, 2007).

\section{CITA ENTERPRISE INNOVATION NETWORK (EIN)}

\subsection{Background}

CITA was selected as one of the three networks in Ireland for funding by Enterprise Ireland under the new EIN programme. The project commenced in 
early October 2008 and is funded by Enterprise Ireland for a three year period. The project will promote ICT and its use in the Irish Construction Industry. The project will involve carrying out detailed research into the particular needs of CITA SME members and other potential new members.

Initially the objectives of this research is to identify the eBusiness and eTendering software products tools and platforms available or potentially available to meet the business needs of SMEs in the construction industry in Ireland. The next phase will be to provide a development strategy for deploying these tools and platforms and the opportunity for CITA to supply an interactive service to its members. The research will also focus on similar work being undertaken in other countries in order to understand the main directions of technology development. The knowledge extracted from previous research will be analysed and developed to meet future requirements.

The specific services that the EIN network will provide to its members are as follows:

- An initial one-one ICT consultation IT sanity check, advice on available software packages and backup and data protection policies.

- Access to the virtual EIN.

- Receipt of regular CITA EIN bulletins.

- An invitation to the CITA EIN intra-disciplinary workshops.

- Exclusive access to all research results undertaken by CITA EIN.

\subsection{Focus on SMEs}

According to Hague and Woodburn (2006) an SME is a business that employs up to 250 employees. However, Hague and Woodburn also observed the fact that over $99 \%$ of SMEs employ less than 50 people and that three quarters of them operate as sole operators.

SMEs operate across most industries from complex electronics to traditional business such as manufacturing. According to the European Union eBusiness W@tch (2006) report, there are approximately 2.4 million construction enterprises in EU25 , of which $97 \%$ are small enterprises with fewer than 20 employees. The industry employs about 14 million people, corresponding to about $7 \%$ of the European work force and $28.5 \%$ of industrial employment.

In the Construction Industry Review and Outlook (2008) prepared by DKM Economic Consultants the authors estimated that in the Irish construction sector close to 100,000 workers or almost $40 \%$ of total persons employed at Q2 2008 worked in companies with less than 5 people. These companies experienced the lowest decline in employment over the past year (DKM, 2008). In the Central Statistics Office (CSO) Report (2007), SMEs in the construction sector boom reported that more than half of the 227,400 workforce in the sector at that time were either self-employed or worked for companies with less then 10 people. However, the research also noted that small enterprises generally make less use of more advanced ICT than larger companies. Just under half of small enterprises engaged in innovation activity in 2004 compared with two thirds of larger enterprises (CSO, 2007).

It is expected that a clear indication of the eBusiness and eTendering IT needs and opportunities for SMEs in the construction industry will become evident. A research programme will be undertaken to identify and analyse:

1. The eBusiness and eTendering software products and services currently available to construction industry SMEs in Ireland.

2. eBusiness and eTendering software products and services available to construction industry SMEs in other relevant countries, which may not be available in Ireland.

3. Current research programmes in other countries which may have a direct bearing on the IT needs of the Irish Construction Industry.

The information received from this analysis combined with the information emerging from the meeting programmes and technology check of EIN members will chart a course for greater effectiveness and efficiency for SMEs in the construction industry, through the use of ICT.

\subsection{Methodology}

The CITA EIN project will follow a formula that is similar to the successful CITAX project discussed earlier in this paper.

- Project Planning - promoting the message of the potential of ICT to the SME sector in the construction industry.

- Services currently available - the research data assembled in the CITAX project would be used to classify the products and services. A product/service database would be compiled.

- Services currently available in relevant countries by contacting suppliers of software products and platforms used by SMEs in relevant countries, data and services of relevant products would be added to the service database.

- Current research programmes - a literature and web-based review will be undertaken of the current research programmes identifying the direct relevance to the use of ICT by SMEs.

- Review of the SME needs - findings from the product/service research will be compared with the outcome of the SMEs discussion meetings and the findings from the technology check programme to 
screen and prioritise the identified products, services, platforms and research programmes.

- Strategy Development - develop a strategy to assist in the development and implementation of the best products, services, platforms and ideas, derived from earlier modules.

\subsection{Key Performance Indicators}

Table 1 below indicates a metrics of performance for the CITA EIN project. The six key performance indicators are measurable and reflect the impact of the work to be carried out. These performance indictors will be addressed and assessed at CITA's general meetings in order to evaluate the progress of the research.

\subsection{Progress to-date}

As part of the research into defining the services that will be provided to the EIN members, a series of interviews have already be undertaken with companies that represent a broad spectrum of activity within the construction industry. This spectrum of companies included; one quantity surveying practice, three suppliers, one engineer and four architects. Most of the companies interviewed have reasonable ICT infrastructure and the majority of the companies have specific software to address particular elements of the construction process for example, traffic model simulation. The main problems identified were lack of adequate disaster recovery planning and high capacity broadband. However, the current economic climate has made a number of companies focus on the short term revenue.

To date, in year 1, CITA has attracted 16 SMEs to join the network.

\begin{tabular}{|l|l|l|l|l|}
\hline \multicolumn{1}{|c|}{ Metric Description } & $\begin{array}{c}\text { Year 1 } \\
\text { Metrics }\end{array}$ & $\begin{array}{c}\text { Year 2 } \\
\text { Metrics }\end{array}$ & $\begin{array}{c}\text { Year 3 } \\
\text { Metrics }\end{array}$ & Total \\
\hline $\begin{array}{l}\text { Number of new SME members joining } \\
\text { CITA. } \\
\text { Measure: Additional new members }\end{array}$ & 40 & 100 & 150 & 290 \\
\hline $\begin{array}{l}\text { SME IT Conference } \\
\text { Attendance to match/exceed the number } \\
\text { of new SME members. } \\
\text { Measure: Number of conferences }\end{array}$ & 1 & 2 & 2 & 5 \\
\hline $\begin{array}{l}\text { Steering group established and meeting on } \\
\text { a regular basis } \\
\text { Measure: Number of meetings }\end{array}$ & 1 & 4 & 4 & 9 \\
\hline $\begin{array}{l}\text { A minimum of 2 working groups } \\
\text { established and meeting regularly to } \\
\text { deliver agreed objectives } \\
\text { Measure: Number of group meetings }\end{array}$ & 6 & 24 & 24 & 54 \\
\hline $\begin{array}{l}\text { Number of companies undertaking } \\
\text { eBusiness }\end{array}$ & 0 & 30 & 100 & 130 \\
\hline $\begin{array}{l}\text { Number of companies tendering } \\
\text { electronically }\end{array}$ & 0 & 40 & 100 & 140 \\
\hline
\end{tabular}

Table 3. CITA EIN Key Performance Indicators

\section{RESEARCH FINDINGS}

\section{1 eBusiness and eTendering Software Products and Services Currently Available}

It is widely accepted that ICT is a key element of any organisational infrastructure. Indeed, many like to think that the level of an organisation's reliance on ICT in the twenty-first century is similar to the reliance on electricity in the previous century where it was not expected for an organisation to function without electricity (Alshawi, 2007).

Enterprise Resource Planning (ERP) system software is a software platform that provides the best ways to improve the co-operation and interaction between all departments in organisations (such as product planning, manufacturing, purchasing, marketing and customer service department). In recent years many ERP system suppliers have produced a new package for SMEs such as mySAP, Oracle Small Business Suite, Navision (Nazor, 2008).

At present there are several major vendors competing in the BIM market;

Autodesk (Revit \& AutoCAD-based applications); Revit architecture is the best known and current market leader for the use of BIM in architectural design. Autodesk's premier building application on the AutoCAD platform is Architectural Desktop (ADT). ADT was Autodesk's original 3D building modelling tool prior to the acquisition of Revit.

- Bentley Systems; Bentley systems offers a wide range of related products for architecture, engineering, and construction. Their architectural BIM tool, Bentley Architecture, introduced in 2004, is an evolutionary descendent of Triforma, integrated with Bentley Architecture.

- ArchiCAD (Graphisoft); ArchiCAD is the oldest continuously marketed BIM architectural design tool available today. Graphisoft began marketing ArchiCAD in the early 80 's. It is the only objectmodel-oriented architectural CAD systems running on the Apple Macintosh.

- Telka Structures; Tekla Structures is offered by Tekla Corporation, a Finnish company founded in 1996 with offices worldwide. Tekla has multiple divisions, construction, infrastructure and energy (Eastman et al, 2008).

In October 2007 RICS e-Tendering was launched by the then Minister for Construction in the UK Stephen Timms MP. Building Cost Information Service had partnered with BravoSolution an Italian based company founded by a construction based organisation Italcementi Group (provide a general eprocurement service) to provide the infrastructure for the RICS service. At the time BravoSolution 
were the framework supplier to the Office of Government Commerce (OGC) supplying e-procurement solutions to the UK public sector (Martin, 2008).

A key necessity for any future business strategy is to effectively support the full lifecycle of a company's product with a process that enables collaboration along and across partner networks. This service is known as Product Lifecycle Management (PLM). Dassault Systèmes, is a vendor that can provide this service (ENOVIA V6 platform) and its main strategy is focused on providing PLM solutions to SMEs.

E-Business is the first and most critical step in which the companies must be established in order to guarantee their survival and stability (Balciunaitis, 2008). As part of CITAs EIN initiative to promote ICT and innovation in SMEs in the construction industry, a software directory has been created with an index of ICT vendors. The future process is to establish these vendors into software categories such as; Feasibility / Design / Project Management / Quantity Surveying and Document Control. This list of eBusiness and eTendering software products currently available will allow CITA to conduct its methodology and develop a strategy to assist in the development of the best products, services, platforms and ideas.

\section{RELATED INTERNATIONAL RESEARCH}

\subsection{RICS (Royal Institution of Chartered Surveyors)}

In 2006 the Building Cost Information Service (BCIS) carried out a survey into current tendering procedures. The construction and building research conference survey was sent to 4000 partner/director members of the RICS Quantity Surveying (QS) and Construction. 298 surveys were completed, representing a response rate of $7.4 \%$. The survey showed the hesitation by the industry to deploy eTendering methods. Only $8 \%$ of tenders were sent out in electronic format while a further $27 \%$ were sent in paper and electronic format. Only $7 \%$ of the documents distributed in electronic format were made available via the web. However, nearly $90 \%$ agreed that eTendering lowered administration costs and nearly three-quarters thought that the ability to tender projects electronically would enhance their company's service (Martin, 2008).

\section{$6.2 e-N V I S I O N$}

In according to Tarka (2008) the main contribution to the construction industry is not the development of another powerful platform, but the definition and conceptualisation of new eBusiness scenario and the development of a data model that will provide the basis of standardisation of the concepts managed in construction processes.
The overall objectives of e-NVISION is to

- use e-Business platforms to enable SMEs to model and adapt particular business scenarios requested by their customers and suppliers;

- to integrate all their enterprise applications following a service-oriented architecture; and to incorporate legal, economical and social services, with the final goal of facilitating their participation in the Future European eBusiness Scenarios.

Four future scenarios were identified by eNVISION based on know-how (knowledge and experience) of SMEs involved in projects and how they would work in the future, such as; e-Tendering, e-Site, e-Procurement and e-Quality (Tarka, 2008).

\subsection{Organisation for Economic Co-operation and Development (OECD)}

The OECD is one of the world's largest and most reliable sources of comparable statistics and economic and social data. Researching on social changes or evolving patterns in such sectors as trade, environment and technology are some of the key services provided by the organisation. In reference to the OECD's published report ICT, eBusiness and SMEs (2004), ICT applications are recognised as having the ability to improve information and knowledge management inside a firm and can reduce transaction cost and increase the speed of transaction for both business-to-business (B2B) and business-toconsumer (B2C). The use of ICT by SMEs is increasingly common in a Eurostat survey on ecommerce. Nine out of ten SMEs were equipped with computers at the end of 2000/early 2001. However it was noted that across the sector internet penetration is generally higher in larger enterprises (OECD, 2004).

\subsection{CIFE Centre for Integrated Facility Engineering}

The CIFE mission is to be the world's premier academic research centre for Virtual Design and Construction of AEC industry projects. Cheng et al (2008) CIFE Technical Report discusses a web service framework that connects, invokes and integrates loosely coupled, heterogeneous information sources and platforms. The report analyses the traditional method of conventional centralised portal systems which is an effective tool in collaboration and interoperability in a construction supply chain. However the issues of information ownership rights and proprietary privacy hinder sharing among companies, as companies prefer to have their own database system. In distributed network architecture, each or- 
ganisation has its own database and portal system. The database and portal system are hosted by either one organisation or a third party. The network grants the rights to view or access data and documents for a specific period of time. SC Collaborator is the prototype web-based platform that is designed to provide an economical and desirable platform for AEC companies, which are usually SMEs in size and are often reluctant to invest in a system that requires frequent changes.

The report illustrates two example scenarios; Procurement interactions and material delivery management. In the procurement interaction scenario the usual prolonged dependency on time and configuration of communication channels between buyer and supplier are quickly removed in the SC Collaborator due to its service architecture. The organisation simply creates an account in SC Collaborator for their trading partner, and exchange IP addresses which facilitates the addition, replacement and removal of trading partners.

The second scenario (material delivery management) demonstrates the online collaboration and information flow among a general contractor, subcontractor and suppliers using SC Collaborator to manage material delivery. The scenario illustrates how SC Collaborator distributes vital information (delay notices) to the required partners and how the system analyses all options before assisting the subcontractor in making a schedule delay for the affected task which results in the project participants obtaining an updated schedule to plan and revise their tasks (Cheng et al, 2008).

\subsection{ICT Needs Analysis}

In the current age of global and digital economy and virtual teams there has been an increasing interest in trust (Stair, 2008). In order for the supply chain to collaborate, software vendors will need to produce products that are able to integrate with developing environments and produce integrated packages. In Cheng et al, (2008) decentralised portal network architecture is introduced to promote sharing of information and to enable distributed computing. Alshawi, (2007) the future for ICT organisations is not to develop their own application packages but to subscribe to application service provider (ASP) sharing licenses between firms or buying a licence for a commercially available package from a third party. Cyon Research White Paper, (2006) questioned Harvard Business School Professor Clayton Christensen's theory on disruptive innovation. Disruptive innovation identifies that a technological innovation, product, or service will eventually overturn the dominant technology in the market by either filling a role in a new market or moving up the market through performance improvement.
As the use of computers and telecommunications have changed over time, the portfolios of information systems suitable to an era of inward focus automation of basic activities are unlikely to be suited to an age which focuses on information to support executive decision making, connect the organisation to another organisation in the business environment (Razali et al, 2005).

The future of ICT is a service deployed from a centralised data centre across a network providing access to the applications from a central provider (Software as a Service). This solution offers the opportunity for companies to select their ICT priorities and then choose from the growing menu of applications being offered through service providers. With access to a service platform customers can use the latest technology tools integrated with existing infrastructure. The concept of renting rather than buying provides lower initial costs through incurring licenses for the amount that is needed (SIIA, 2001).

For the vendors of SaaS it makes good sense because the vendor can achieve economies of scale. The software as service vendor has a high degree of control over its application and is thus a prime candidate for the adoption of horizontal infrastructure integration strategies ( Foster and Tuecke, 2005).

\section{CONCLUSION; THE FUTURE SCENARIO}

As one look forward, there would not be a single shared vision of the nature of construction process and product delivery to which all future research would relate. However, for the benefit of making our respective implicit visions more visible, it is possible to construct scenarios of the future to which our ongoing research efforts may relate (Amor et al, 2002).

The CITA EIN programme anticipates that by developing a strong and proactive EIN it will encourage SMEs to use electronic business. Through detailed research into the particular future business needs of CITA SME members and other potential new members combined with information emerging from meeting programmes and technology checks the effectiveness and efficiency of SMEs in the Irish construction industry will materialise.

The success and effectiveness of ICT in today's world economies have clearly shaped our environment. ICT has improved our supply chain management process, communication ability and business, and still new innovative solutions are being adapted. However, taking other industries into consideration the construction industry still trails behind, being reluctant to shift from traditional techniques. The downward adjustment in the Irish construction sector has presented the industry with the new challenge of remodelling and rethinking ICT. The largest amount of persons employed in the construction industry in Ireland work for small enterprises. These small enterprise make less use of more advanced 
ICT than large companies and are generally credited as the main contributor to the reluctance of ICT uptake. However, it is widely acknowledged that if SMEs increase the practice of using ICT they will develop and become more efficient which will able them to compete more effectively both in their domestic and overseas markets.

The aim of CITAs EIN research programme and development process methodology clearly identifies a staged programme that has the ability to address the need to promote ICT in the Irish construction industry and research SMEs pattern needs to develop a strong eBusiness environment. It is CITA's vision that by creating a digital community and carrying out research that will identify the more effective products, CITA will be providing a service to the Irish construction SME industry that will enable them to have the opportunity to compete on the global stage with the industry's most enhanced and effective ICT products. It is extensively accepted that a specialised software provider can target global markets; a hosted application such as CITA could instantly reach an entire market, making specialization within a vertical market not only possible, but preferable. The future scenario of ICT is SaaS. It allows SMEs in the construction industry to have access to functionalities and markets which were previously only the domain of large enterprises.

\section{REFERENCES}

- Alshawi, M. (2007), Rethinking in Construction and Engineering, Organisational Readiness, Talyor \& Francis, Oxon.

- Amor, R., Betts, M., Coetzee, G. and Sexton, M. (2002), Information Technology for Construction: Recent Work and Future Directions, ITcon, Volume $7, \quad 245-258, \quad$ available on http://www.itcon.org/2002/15

- Balciunaitis, G., Ciumanovas, V. and Gricius, R. (2008), European Conference on Product \& Process Modelling: eWork and eBusiness in Architecture, Engineering and Construction, CRC Press, 703-710.

- Becerik, B. (2004), A Review on Past, Present and Future of Web based Project Management \& Collaboration Tools and their Adoption by the US AEC Industry, International Journal of IT in Architecture, Engineering and Construction, Volume 2, Issue 3, Mill Press, 233-248.

- Central Statistics Office (2007), The Small Business in Ireland Report 2007, CSO publications.

- Cheng, P.C, Law, K. and Bjornsson, H. (2008), A Distributed Portal-Based Platform for Engineering \& Construction Supply Chain Interoperability, CIFE Technical report \#TR173, Centre for Integrated Facility Engineering, Stanford University.
- Cyon Research (2006), The Business Case for a Common Data Distribution Platform: A look at UGS' JT, Cyon Research Coporation, available from www.cyonresearch.com

- Department of Enterprise, Trade and Employment (DETE), 2004, eBusiness Strategy: Optimising usage of ICTs by Irish SMEs and micrenterprises, Irish Government Publications, Dublin.

- Department of Finance, National Strategic Reference Framework (NSRF), 2007, Supporting and Enabling Dynamic Regions: EU Policy 20072013, Irish Government Publications, Dublin.

- DKM Economic Consultants (2008), Review of the Construction industry 2007 and Outlook 2008 to 2010

- Duffy, K., Graham, B. and Thomas, K. (2007), Assessing the Potential for Construction Collaboration Technologies (CCT) in Small to Medium Enterprises in the Irish Construction Industry. In: Boyd, D (Ed) Procs $23^{\text {rd }}$ Annual ARCOM Conference, 3-5 September 2007, Belfast, UK, Association of Researchers in Construction Management, 461-462.

- Eastman, C., Teicholz, P., Sacks, R. and Liston, K. (2008), BIM Handbook, A Guide to Building Information Modeling for Owners, Managers, Designers, Engineers, and Contractors, John Wiley and Sons, America.

- Enterprise \& Industry Directorate General (2006), e-Business W@tch: ICT and e-Business in the Construction Industry, Sector Report No.7/2006.

- European Commission (2007), Sectoral eBusiness Policies in Support of SMEs, Innovative Approaches, Good Practices and Lessons to be learned, eBSN Report, 43-46.

- European Commission (2009), Software 2.0: Rebooting Europe's Software Industry, Report of an Industry Expert Group on a European Software Strategy, Version 3.0

- Foster, I. and Tuecke, T. (2005), Describing the Elephant: The Different Faces of IT as Service, Q Focus, Enterprise Distributed Computing, Queue July/August 2005, available on www.acmqueue.com

- Gallaher, M.P, O'Connor, A.C, Dettbarn, J.L and Gilday, L.T, (2004), Cost Analysis of Inadequate Interoperability in the U.S. Capital Facilities Industry, U.S Department of Commerce Technology Administration, National Institute of Standards and Technology (NIST), American Government Publication, Maryland.

- Gatautis, R. and Vitkauskaite, E. (2008), European Conference on Product \& Process Modelling: eWork and eBusiness in Architecture, Engineering and Construction, CRC Press, 2008, 673-680.

- Hague, P and Woodburn, S (2006) Small \& Medium Enterprises Equal Big Opportunities, B2B International Ltd 
- Hore, A.V and West, R.P. (2005), "Attitudes towards Electronic Purchasing in the Irish Construction Industry", 2005 CIB W92/T23/W107 International Symposium on Procurement Systems, Las Vegas, USA.

- Hore, A.V and West, R.P, 2008, CITAX: A Collaborative ICT Standards Model for the Irish Construction Industry, CIB W78, 25 ${ }^{\text {th }}$ International Conference on Information Technology in Construction, Santiago, Chile, $15^{\text {th }}-17^{\text {th }}$ July 2008.

- Martin, J. (2008), E-tendering-about time too, Royal Institution of Chartered Surveyors publication

- National Economic Social Council (NESC), 2004, Housing in Ireland: Performance and Policy, Irish Government Publications, Dublin.

- Nazor, I. (2008), "Selling" Restructuring to SMEs through ERP Implementation, Centar za strucne studije Sveucilista u Splitu, available from http://www.fer.hr/_download/repository/Kvalifik acijski_ispit_rad.pdf

- Organisation for Economic Co-operation \& Development (2004), ICT, E-Business and SMEs, OECD publication.

- Razali, M.N., Sahir, I.Y., Manaf, N. and Othman, S.H. (2005), The Design of Best Practice Framework in Information and Communication Technology Management in Facilities Management: Case Study in Malaysia, 2005 CIB International Symposium on Advancing Facilities Management and Construction through Innovation, Helsinki, Finland.

- Software and Information Industry Association (2001), Software as a Service: Strategic Backgrounder, SIIA publication, Washington, DC, U.S

- Stair, R., Reynolds, G. and Chesney, T. (2008), Principles of Business Information Systems, Cengage Learning EMEA.

- Tarka, M. (2008), European Conference on Product \& Process Modelling: eWork and eBusiness in Architecture, Engineering and Construction, CRC Press, 2008, 691-701. 